\title{
SAUNG ANGKLUNG UDJO MENDUNIAKAN SENI PERTUNJUKAN TRADISI
}

\author{
Taessia Andina $^{1)}$, Dendi Pratama ${ }^{2)}$ \\ Program Studi Desain Komunikasi Visual, \\ Fakultas Bahasa dan Seni, Universitas Indraprasta PGRI \\ JL. Nangka No 58 C, Tanjung Barat, Jakarta 12530, Indonesia \\ Andinatasya03@gmail.com
}

\begin{abstract}
Abstrak
Di era globalisasi pada saat ini kesenian budaya menciptakan sebuah tantangan baru bagi kalangan masyarakat untuk meningkatkan kreativitas dalam mengelola berbagai kesenian budaya dan tradisi lokal. Beragam dampak dari munculnya era globalisasi budaya pada saat ini dapat diantisipasi jika proses inovasi dan kreativitas terus berlangsung dan berkembang di masyarakat. Melalui metode kualitatif, kajian ini akan mencoba untuk menjelaskan bahwa Saung Angklung Udjo merupakan suatu invensi tradisi yang terbentuk melalui proses kreatif pengembangan seni tradisi. SAU sebagai suatu invensi tradisi sangat terkait dengan peran agensi individu merespons realitas seni tradisi melalui pendirian sanggar angklung. Agensi individu ini merancang kondisi sosial dan lingkungan dengan menciptakan sanggar angklung yang keberadaannya merujuk pada seni tradisi angklung sebagai bagian dari budaya masyarakat Sunda. Kemampuan agensi individu ini melakukan invensi tradisi melalui formalisasi dan ritualisasi kegiatan pendidikan, produksi, dan pertunjukan angklung. hal tersebut dapat menjadi modal bagi pelaku seni tradisi untuk berinovasi dan lebih meningkatkan kreativitas dalam menghadapi tantangan globalisasi budaya.
\end{abstract}

Kata Kunci: Menduniakan Seni, Seni Tradisi, Saung Angklung Udjo

\begin{abstract}
In the current era of globalization, cultural arts create a new challenge for the community to improve creativity in managing various cultural arts and local traditions. Various impacts from the emergence of the era of cultural globalization at this time can be anticipated if the innovation and creative processes continue and develop in the community. Through qualitative methods, this study will try to explain that Saung Angklung Udjo is a traditional invention that is formed through the creative process of developing traditional arts. SAU as a traditional invention is closely related to the role of individual agencies responding to the reality of traditional art through the establishment of an angklung studio. This individual agency designs social and environmental conditions by creating an angklung studio whose existence refers to the art of angklung tradition as part of Sundanese culture. The ability of these individual agencies to carry out traditional inventions through formalization and ritualization of educational activities, production and angklung performances. this can be a capital for traditional art practitioners to innovate and further enhance creativity in facing the challenges of cultural globalization.
\end{abstract}

Keywords: Familiarize Arts, Arts Traditional, Saung Angklung Udjo

Correspondence author: Name, E-mail, City, and Country 


\section{PENDAHULUAN}

Mengelola seni tradisi merupakan suatu permasalahan yang dihadapi masyarakat dan negara di era globalisasi saat ini. Dengan merebaknya seni seni popular yang digaungkan negara-negara maju yang menginfus pola pikir serta gaya hidup generasi muda Indonesia saat ini, menjadikan seni tradisi semakin termajinalkan. Mengelola seni tradisi pun seakan bukan menjadi pilihan yang baik, mengakibatkan seni-seni tradisi yang pernah hidup, berkembang dan menjadi semangat masyarakat Indonesia yang kian perlahan mulai memudar dan sirna. Masyarakat lebih familiar dengan seni-seni modern yang dengan mudah dapat dinikmati pada perangkat elektronik, alihalih menikmati seni tradisi yang harus dilakukan oleh banyak orang untuk dapat dinikmati. Komunitas-komunitas seni tradisi pun ikut membubarkan diri, seiring semakin sulitnya bertahan dan mempertahankan hidup dengan bergantung pada seni jenis ini.

Kondisi ini tentu mengkhawatirkan bagi kita sebagai masyarakat yang berkembang dan dibesarkan dari kearifan lokal nenek moyang karena dari seni tradisilah kita belajar "hidup", dari seni tradisi ini pula masyarakat membentuk sistem pengetahuan dan kebudayaan, dan kemudian membentuk suatu peradaban. Dengan memelajari kebudayaan sendiri maka konstruksi masyarakat menuju satu bangsa yang memiliki peradaban sesuai dengan ciri dan identitas sendiri, yang kemudian direalisasikan dalam kehidupan sehari-hari maka diharapkan akan memberi manfaat bagi perkembangan kehidupan masyarakat kita kearah yang lebih baik sesuai dengan cita-cita dan tujuan dari berbangsa dan bernegara.

Oleh karena itu, berdasarkan uraian di atas sangat diperlukan adanya suatu kesadaran dalam mengelola seni tradisi karena seni tradisi merupakan manifestasi pendidikan humaniora yang membentuk jalinan relasi sosial-ekonomi dan kultural masyarakat yang dapat kita klasifikasikan sebagai cultural engineering masyarakat. Mempelajari kembali bagaimana seni tradisi memengaruhi kehidupan masyarakat, menjadi pengikat hubungan dan menjadi kekuatan ekonomi, merupakan suatu hal yang harus dilakukan saat ini untuk mengembalikan karakter bangsa Indonesia yang semakin terkikis dan tergantikan dengan pola kehidupan barat.

Untuk itu, dalam tulisan ini akan dibahas bagaimana salah satu komunitas yang dianggap berhasil dalam mengelola seni tradisi, melalui perjalanan dan perjuangan yang panjang, tetapi mencapai tingkat kesuksesan yang diakui, bukan hanya di lingkungan sekitar, lokal, negara, bahkan sampai ke kalangan internasional.

Komunitas tersebut adalah Saung Angklung Udjo, yang kini telah menjadi suatu lembaga berbadan hokum adapun aktivitas utamanya adalah mengembangkan, melestarikan dan memopulerkan kesenian angklung, seni tradisi khas Sunda. Saung Angklung Udjo, bukan hanya berhasil menghidupkan seni tradisi, tetapi juga menghidupkan sosial-ekonomi masyarakat sekitarnya. Saung Angklung Udjo telah berhasil menjadi lembaga budaya yang memahami dengan baik fungsi dan peran lembaga budaya, isi, dan peran produk budaya, serta peran budaya dalam masyarakatnya.

\section{METODE PENELITIAN}

Metode yang digunakan dalam penelitian ini adalah metode penelitian kualitatif. Penelitian kualitatif ialah prosedur penelitian yang menghasilkan data deskriptif berupa kata-kata tertulis atau lisan dari orang-orang dan perilaku yang diamati (Bodgan dan Taylor, 1993). Teknik pengumpulan data yang digunakan adalah tinjauan pustaka, yaitu mengumpulkan beberapa pustaka kemudian dianalisis dan selanjutnya disimpulkan.

\section{HASIL DAN PEMBAHASAN}

\section{Saung Angklung Udjo}

Saung Angklung Udjo didirikan pada tahun 1966 oleh Udjo Ngalagena (alm) yang akrab disapa dengan panggilan Mang Udjo dan sang isteri bernama Uum Sumiati. Pada awalnya Saung Angklung Udjo hanya memanfaatkan teras kecil rumah Mang Udjo di Jalan Padasuka 118 Bandung, seiring dengan perkembangannya, Mang Udjo mulai melebarkan lahan rumahnya dengan membeli tanah dan rumah tetangga-tetangganya. 
Saat ini Saung Angklung Udjo merupakan sanggar seni sebagai tempat pertunjukkan seni, laboratorium pendidikan sekaligus sebagai objek wisata budaya khas Jawa Barat, dengan mengandalkan semangat gotong royong antarsesama warga.

Saung Angklung Udjo yang terletak di Jalan Padasuka 118 Bandung, pada awalnya hanya berupa teras kecil rumah pasangan Udjo Ngalagena, kini telah memiliki area seluas lebih dari 1,5 hektare. Pada area tersebut terdapat teater utama tempat pergelaran angklung dan seni Sunda lainnya dengan kapasitas mencapai 1000 (seribu) penonton dengan desain yang sederhana dan terkesan alami. Memasuki gerbang Saung Anglung Udjo yang terbuat dari bambu, akan langsung terasa kesan damai dan nyaman. Loket pembelian tiket langsung terhubung dengan toko cenderamata dan teater utama, sedangkan di area belakang bisa dilihat aktivitas pengrajin angklung. Selain aktivitas pengrajin angklung, kegiatan di Saung Angklung Udjo berlangsung setiap hari kecuali hari raya Iduladha dan Idulfitri.

Aktivitas setiap hari dimulai sekitar pukul 2 (dua) siang, di mana anak-anak masyarakat sekitar Saung Angklung Udjo yang juga para pemain, setelah pulang sekolah, mereka mulai belajar bahasa Inggris dan dilanjutkan latihan menari / bermain angklung, serta setiap pukul 15.30 s.d. pukul 17.30 wib anak-anak dan remaja melakukan pertunjukan yang selalu dipenuhi oleh penonton baik dari dalam negeri dan tentunya paling banyak wisatawan mancanegara. Pertunjukan setiap sore tersebut dibuka dengan pergelaran Wayang Golek, tetapi pergelaran ini tidak menampilkan cerita Wayang Golek secara utuh, karena akan memakan waktu yang sangat panjang. Pergelaran Wayang Golek ditampilkan hanya untuk mengenalkan salah satu kesenian Sunda, bahkan yang menarik, panggung Wayang Golek dibuka sehingga penonton dapat melihat gerakan kaki dalang yang juga ikut berperan menggerakkan wayang tersebut. Namun, pada saat ini pertunjukan wayang golek tidak lagi memperlihatkan gerakan kaki dalang, hanya saja yang di pertunjukan pagelaran wayang goleknya saja.

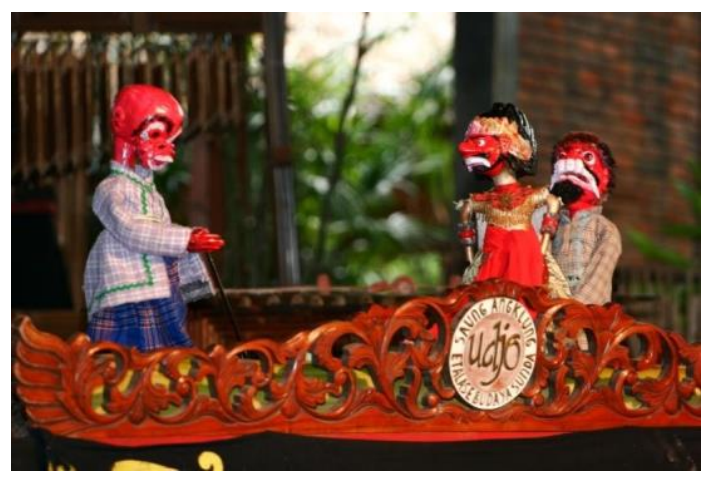

Gambar 1 Pergelaran Wayang Golek Sunda

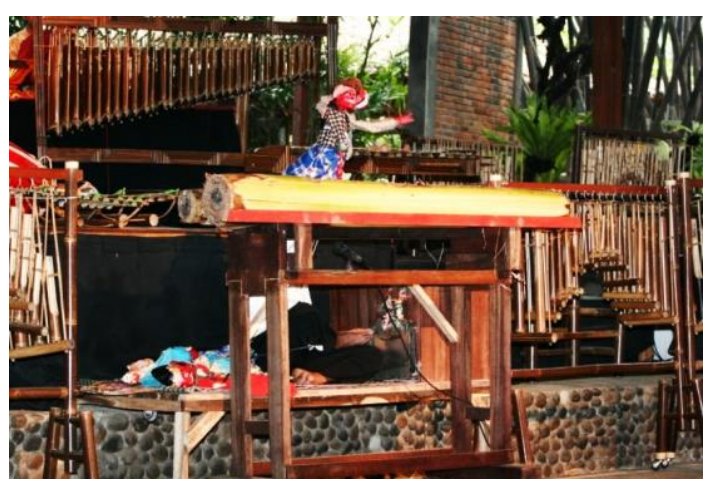

Gambar 2 Penutup panggung Wayang Golek dibuka 


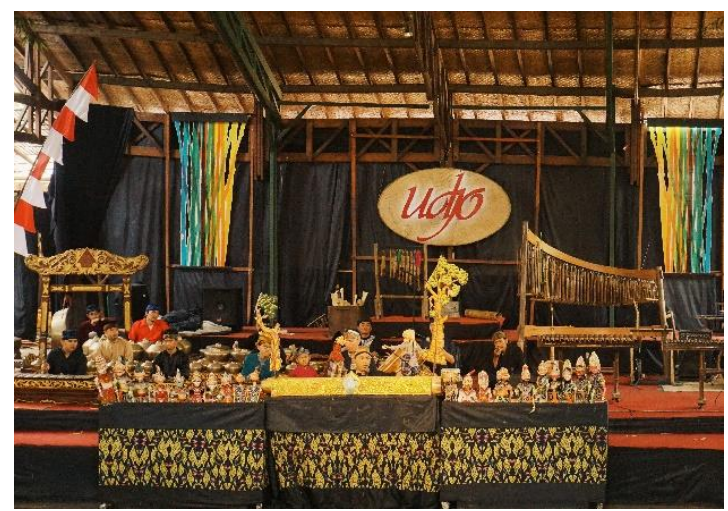

Gambar 3 Pagelaran Wayang Golek Sunda Pada Saat Ini

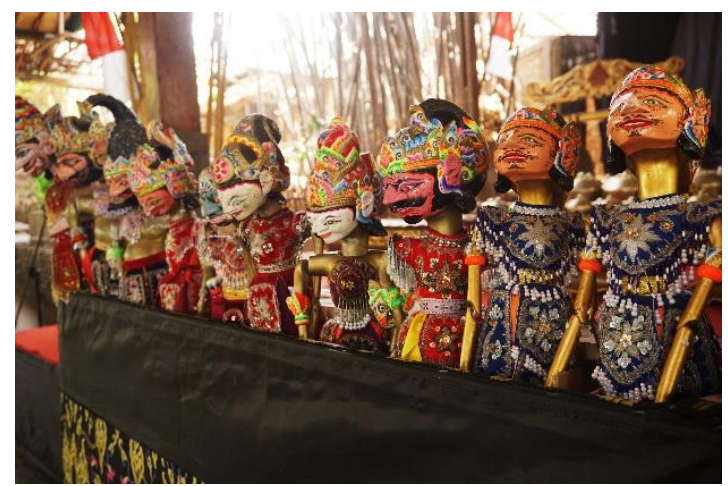

Gambar 4 Koleksi Wayang Golek yang ditampilkan Pada saat Pagelaran

Pertunjukan berikutnya adalah "Helaran", yaitu semacam tarian iring-iringan upacara khitanan atau upacara rasa syukur terhadap keberhasilan panen yang disusul oleh tari topeng khas Sunda serta pergelaran seni lainnya, yaitu Alunan Rumpun Bambu, dan dilanjutkan dengan bermain angklung bersama penonton.

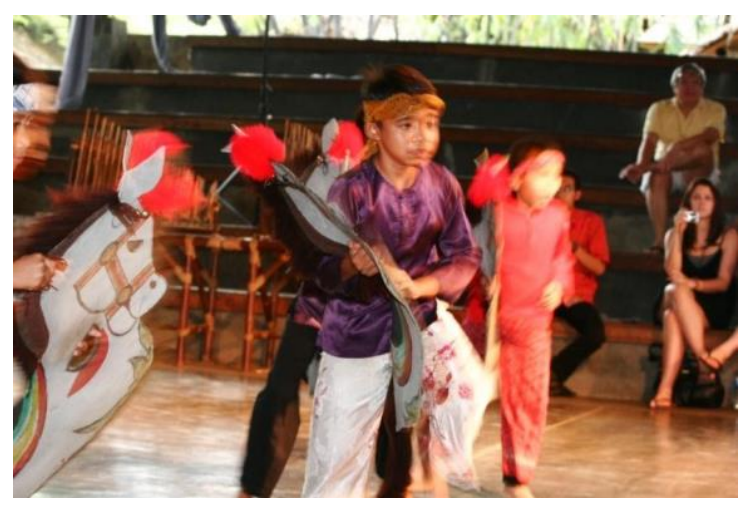

Gambar 5 Tarian kuda lumping pengiring helaran 


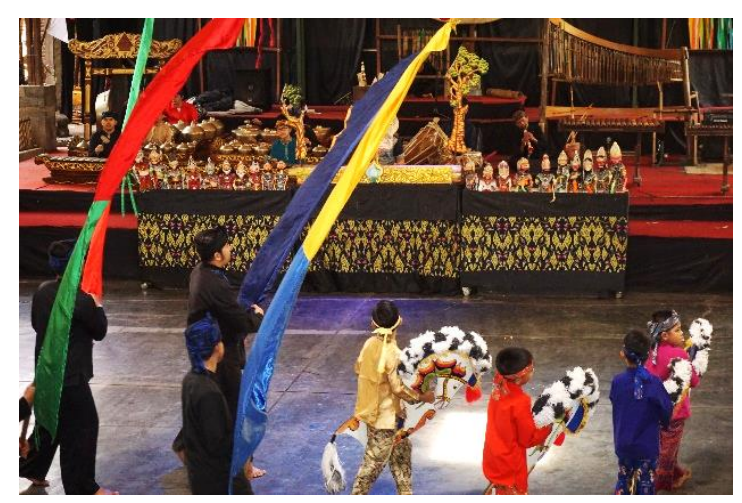

Gambar 6 Tarian kuda lumping pengiring helaran Pada saat ini

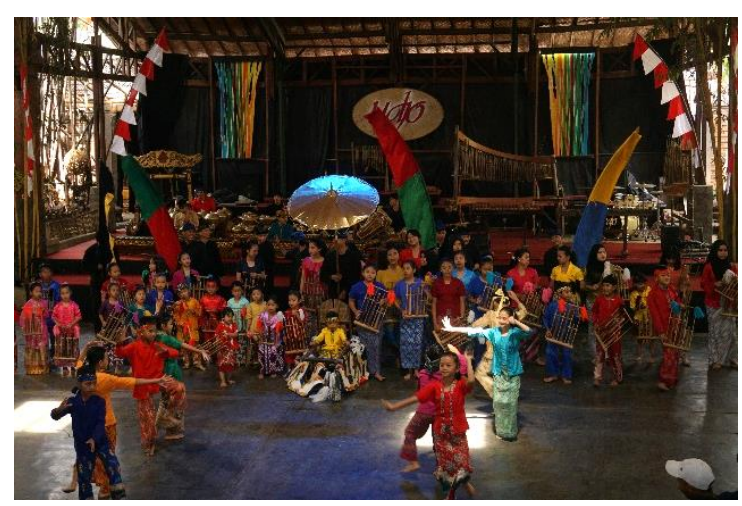

Gambar 7 Helaran khitanan

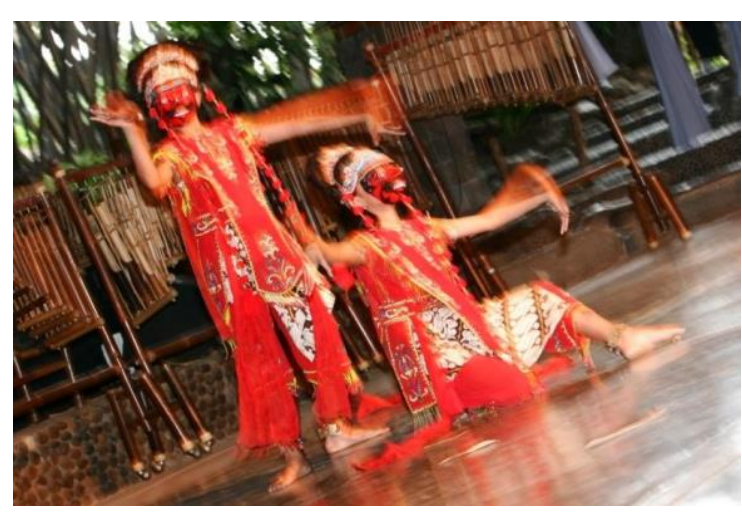

Gambar 8 Tari Topeng 


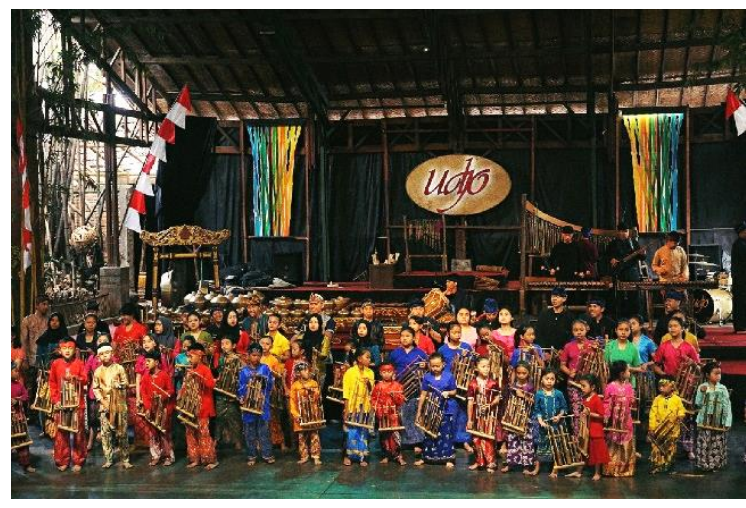

Gambar 9 Harmonisasi Angklung

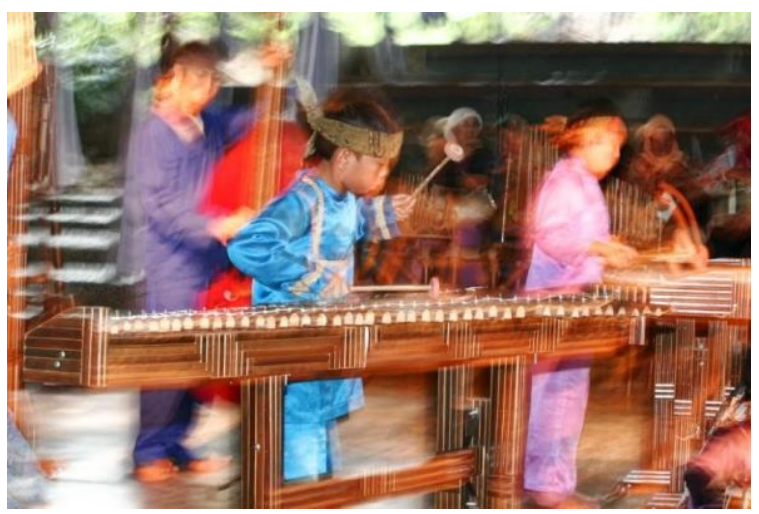

Gambar 10 Alunan Rumpun Bambu

Pada acara terakhir ini, seluruh pemain pada Saung Angklung Udjo, menyebar dan bergabung dengan pengunjung, mereka membagikan angklung kepada pengunjung dan mengajarkan menggoyangkan angklung agar menghasilkan bunyi. Setelah itu, bersama-sama mengikuti arakan konduktor untuk memainkan lagu dengan menggoyangkan angklung secara bergantian sesuai instruksi pemimpin.

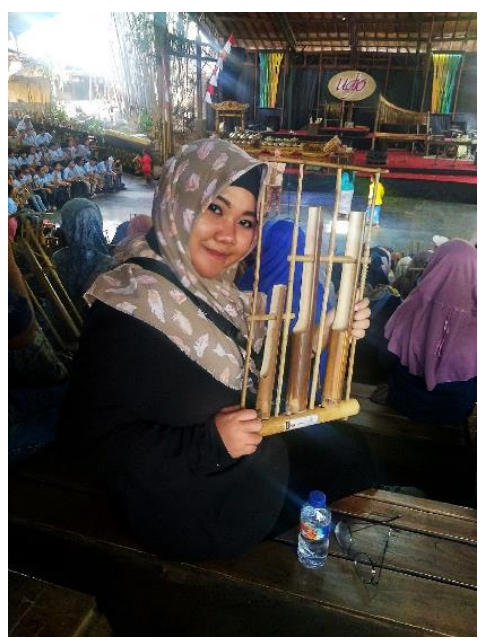

Gambar 11 Interaktif Angklung pada pengunjung 
Namun, pada saat ini pertunjukan Saung Angklung Udjo sudah dibagi menjadi beberapa sesi pertunjukan, yaitu dimulai dari Pagi hari pukul 10.00 - 11.30, Siang hari pukul 13.00 - 14.30, Reguler/Petang pukul 15.30 - 17.00 dan Malam hari pukul 18.30 - 20.00 jadwal tersebut berlaku pada hari Senin - Jumat dan untuk pertunjukan dihari Sabtu-Minggu dimulai pada Petang/Sore hari pukul 15.30 - 17.00 dengan harga tiket yang lebih mahal dibanding hari biasanya.

\section{Manajemen Saung Angklung Udjo}

Pada awal pendirian Saung Angklung Udjo merupakan usaha keluarga, seiring dengan perkembangan dan kebutuhan, mulai pada tahun 1995 dilakukan penataan dan berorientasi pada profit. Sejak saat itu, Saung Angklung Udjo kemudian memiliki badan hukum berbentuk perusahaan terbatas, yang dikelola langsung oleh Udjo Ngalagena dan putra-putrinya. Setelah Udjo Ngalagena meninggal, usaha ini diteruskan oleh putra-putrinya (ada 10 orang), dengan Taufik Udjo sebagai pimpinan. Saung Angklung Udjo tidak hanya dikelola oleh putra dan putri Udjo Ngalagena, tetapi juga menunjuk orang lain yang tidak memiliki hubungan keluarga sebagai pengelola termasuk beberapa direktur. Hal ini sebagai wujud profesionalitas dalam mengelola Saung Angklung Udjo.

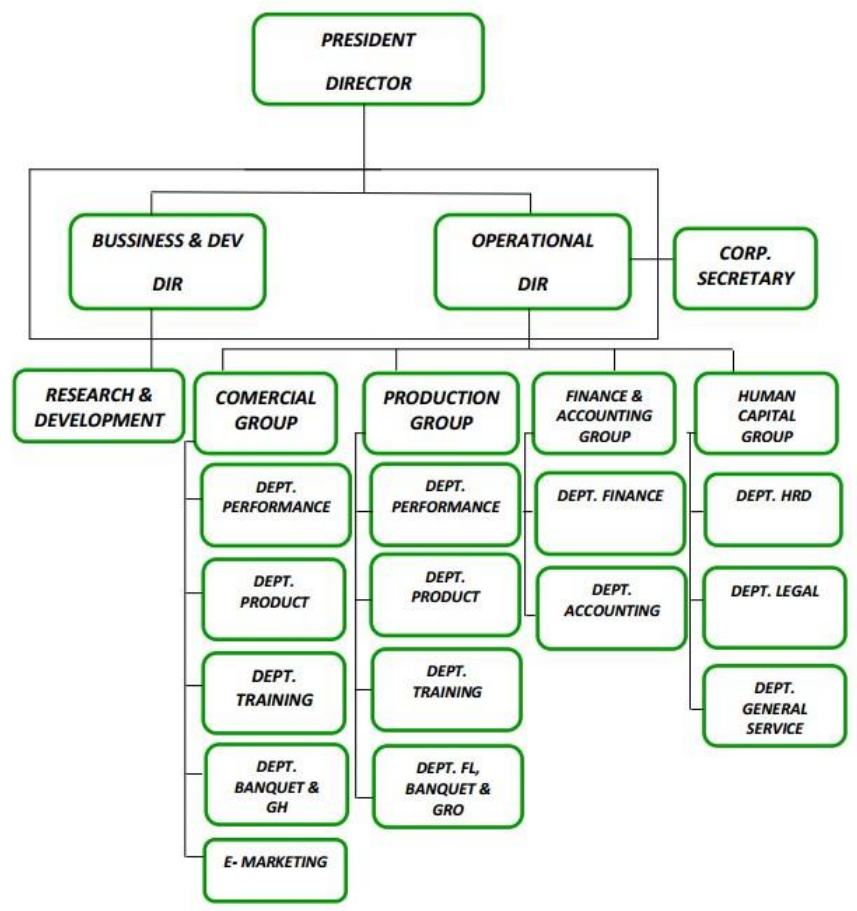

Bagan 1 Struktur Organisasi Saung Angklung Udjo

Sebagai perusahaan, Saung Angklung Udjo memiliki Visi Menjadi kawasan budaya Sunda khususnya budaya bambu yang mendunia untuk mewujudkan wisata unggulan di Indonesia. Visi tersebut kemudian dirumuskan menjadi misi: Melestarikan dan mengembangkan budaya Sunda dengan basis filosofi Mang Udjo, yaitu: gotong royong antarwarga dan pelestarian lingkungan untuk kesejahteraan masyarakat. Selain berbentuk Badan Hukum, Saung Angklung Udjo juga mendirikan yayasan untuk memberikan beasiswa bagi anak-anak di sekitar lokasi Saung Angklung Udjo, sebagai bagian dari bentuk tanggung jawab sosial perusahaan (Corporate Social Responsibility).

Saung Angklung Udjo memberikan beasiswa untuk sekolah melalui orangtuanya, Terdapat sekitar 528 orang anak yang mendapatkan beasiswa dari SAU agar terus sekolah. Saung Angklung Udjo juga menggunakan jasa konsultan marketing untuk mengambangkan usahanya, terutama dari sisi pemasaran, serta melakukan kerja sama dengan Bank Jabar untuk membantu pembiayaan operasional dan pemasarannya. 
Pada saat ini manajemen Saung Angklung Udjo dibagi menjadi 2 unit, yaitu unit bisnis dan unit pendukung, masing-masing membawahkan beberapa unit. Unit-unit tersebut adalah:

1. Unit Bisnis

a. E- Marketing

Bagian Marketing bertangggung jawab atas pemasaran, pemesanan tempat serta penjualan segala produk dan layanan dari Saung Angklung Udjo.

b. Departement Performance

Bagian ini bertugas atas pertunjukkan, kreativitas, kemasan serta inovasi seni dan budaya yang akan ditampilkan dalam pertunjukkan seni. Mereka juga bertanggung jawab untuk membuka pendaftaran pemain baru yang ingin bermain angklung di Saung Angklung Udjo dan mengatur penjadwalan para pemain pertunjukkan.

c. Production Group

Bagian ini bertanggung jawab atas produksi serta pengolahan Angklung dan mengawasi ketersediaan bahan baku utama angklung yaitu: bambu. Selain itu, juga bekerja sama dengan para pengrajin angklung di sekitar daerah Padasuka untuk memproduksi angklung yang semakin tinggi pemintaannya.

2. Unit Pendukung

a. Finance and Accounting Group

Bagian ini bertanggung jawab atas keuangan perusahaan secara keseluruhan serta mengatur keuangan perusahaan.

b. Human Capital Group

Bagian ini bertanggung jawab atas kegiatan serta bidang kepegawaian Saung Angklung Udjo.

Saung Angklung Udjo sebagai perusahaan induk dan sumber pendapatan utama dari bisnis ini adalah pertunjukan dan produksi. Selain pertunjukan, bisnis lain adalah produksi angklung yang dijual pada toko cendera mata yang juga terdapat di Saung Angklung Udjo dan tempat tempat pariwisata, seperti hotel dan restoran di Jawa Barat, terutama kota Bandung. Angklungangklung tersebut sebagian dikerjakan oleh mitra melalui kerja sama kemitraan, di mana sekitar $80 \%$ angklung dihasilkan dari mitra-mitranya.

Namun, teknologi dan kontrol kualitas tetap dilakukan oleh Saung Angklung Udjo. Selain disiapkan toko cenderamata di lokasi Saung Angklung Udjo, pemasaran juga dilakukan melalui web (www.angklung.udjo.co.id), serta bekerja sama dengan 3 (tiga) Kementerian (Kementerian Luar Negeri, Kementerian Pariwisata, dan Kementerian Koperasi). Promosi juga dilakukan melalui mulut ke mulut dari para pengunjung yang puas.

Saung Angklung Udjo juga menerapkan standardisasi mutu, proses pengendalian mutu dilakukan sejak dari tahapan penanaman pohon bambu sampai pada waktu yang tepat pemotongan bambu untuk dijadikan sebagai material pembuatan angklung dan alat musik bambu lainnya.

Saung Angklung Udjo melibatkan masyarakat sekitar untuk berperan aktif dalam setiap kegiatan bisnisnya, seperti pertunjukan yang melibatkan anak-anak sekitar sebagai pemain, para lelaki dewasa banyak yang bekerja sebagai pengrajin dan juga ikut mengelola unit-unit bisnis pada Saung Angklung Udjo.

\section{Jumlah data pengunjung Saung Angklung Udjo}

Jumlah kedatangan pengunjung wisatawan ke Saung Angklung Udjo setiap tahunnya mengalami peningkatan seperti tabel berikut: 
Tabel 1 Jumlah Kunjungan Wisatawan ke Saung Angklung Udjo Tahun 2011-2014

\begin{tabular}{|c|c|c|c|c|c|}
\hline TAHUN & WISNUS & $\boldsymbol{\%}$ & WISMAN & $\boldsymbol{\%}$ & TOTAL \\
\hline $\mathbf{2 0 1 1}$ & 151.938 & 85 & 26.840 & 15 & 178.778 \\
\hline $\mathbf{2 0 1 2}$ & 176.858 & 86 & 29.078 & 14 & 205.936 \\
\hline $\mathbf{2 0 1 3}$ & 177.652 & 86 & 29.260 & 14 & 206.912 \\
\hline $\mathbf{2 0 1 4}$ & 203.529 & 87 & 30.210 & 13 & 233.739 \\
\hline
\end{tabular}

Sumber: Marketing Saung Angklung Ujdo

Tabel 1 di atas menunjukan peningkatan pengunjung wisatawan nusantara dan pengunjung wisatawan mancanegara untuk mengunjungi Saung Angklung Udjo yang setiap tahunnya terus mengalami peningkatan. Namun, dalam kenaikan jumlah kunjungan tersebut tidak semua wisatawan yang sudah pernah mengunjungi Saung Angklung Udjo saja Melainkan wisatawan baru yang datang dengan rekomendasi teman yang sudah pernah berkunjung.

\section{SIMPULAN}

Menilik kembali uraian di atas, Saung Angklung Udjo, membuktikan bahwa seni tradisi bila dikelola dengan baik dan professional sesuai dengan azas-azas manajemen, dapat berjalan dengan baik bahkan bukan hanya memberikan keuntungan bagi pemilik, tetapi juga dapat meningkatkan kesejahteraan bagi masyarakat sekitar.

\section{DAFTAR PUSTAKA}

Bodgan, R., \& Taylor, S. J. (1993). Penelitian Kualitatif. Surabaya: Usaha Nasional.

Handayani, D. (2009). Strategi Bauran Komunikasi Pemasaran Untuk Menarik Minat Kunjungan Wisatawan Lokal dan Mancanegara pada Pariwisata Saung Angklung Udjo di Bandung. Palembang.

Musthofa, B. M., \& Gunawijaya, J. (2017). Saung Angklung Udjo: Invensi Tradisi Lokal yang Mendunia. Antropologi Indonesia.

Saung Angklung Udjo 2014, Website Saung Angklung Udjo, Diakses Agustus 2014 dari http://www.angklung-udjo.co.id/.

Syafii, S. (2009) Udjo: Diplomasi Angklung. Jakarta: Grasindo.

Tedjasendjaja, G. A., \& Dharmadi, S. (2017). Kajian Pelestarian Alat Musik Angklung dalam Bentuk Kampanye Sosial. Rupa Rupa, 2017, 4.2. 